\title{
Erratum to: Eye and skin irritation tests using deep sea water-extracted minerals
}

\author{
Yong Hoon Joo ${ }^{1} \cdot$ Miju Cho ${ }^{1}$ Do Hun Lee ${ }^{1}$ Young Sig Park ${ }^{2}$. \\ Namhyun Chung ${ }^{1}$
}

Published online: 31 December 2016

(C) The Korean Society for Applied Biological Chemistry 2016

\section{Erratum to: J Appl Biol Chem (2016) 59, 233-237 DOI 10.3839/jabc.2016.040}

p. 236

We will modify the Acknowledgments.

The online version of the original article can be found under doi: $10.3839 /$ jabc. 2016.040
Acknowledgments This research was a part of the project titled 'Evaluation of Food Safety on Deep Sea Water Mineral Extract', funded by the Ministry of Oceans and Fisheries, Korea.

Namhyun Chung $(\bowtie)$

E-mail: nchung@korea.ac.kr

Young Sig Park $(\bowtie)$

E-mail: pysku@korea.ac.kr

${ }^{1}$ Department of Biosystems Engineering, College of Life Sciences and Biotechnology, Korea University, Seoul 02841, Republic of Korea

${ }^{2}$ Functional Food Research Center, College of Life Sciences and Biotechnology, Korea University, Seoul 02841, Republic of Korea

This is an Open Access article distributed under the terms of the Creative Commons Attribution Non-Commercial License (http://creativecommons. org/licenses/by-nc/3.0/) which permits unrestricted non-commercial use, distribution, and reproduction in any medium, provided the original work is properly cited. 